\title{
El feminismo: Alfonsina Storni ${ }^{1}$
}

\author{
Yessika María Rengifo Castillo ${ }^{2}$ \\ Héctor José Sanjuas ${ }^{3}$
}

Recibido: 13-02-2018

Aceptado: 16-04-2018

"Yo soy como la loba. Ando sola y me río del rebaño. El sustento me lo gano y es mío/donde quiera que sea, yo tengo una mano lque sabe trabajar y un cerebro que es sano."

Alfonsina Storni.

El feminismo se instaura como un movimiento social que establece la desigualdad, y la discriminación, hacia las mujeres en una sociedad de patriarcado. Ese patriarcado se caracteriza por el dominio de lo masculino sobre lo femenino en aspectos como la razón, la fuerza, y la participación en el espacio público, que son consideradas vertientes superiores a las que solo pueden acceder los hombres. A consideración de los sentimientos, la debilidad, y la esfera doméstica, ejes que "caracterizan" a las mujeres. (Viejo, Cabezas \& Martínez, 2013). Es decir, en ese sistema se posesionan dos líneas: lo masculino y lo femenino, que permea los campos políticos, sociales, económicos, y culturales, que determinan el accionar de hombres y mujeres.

\footnotetext{
1. (Capriasca, Suiza, 1892 - Mar del Plata, Argentina, 1938). Poetisa argentina de origen suizo. Alfonsina Storni pasó a ocupar un lugar destacado en el panorama literario hispanoamericano por la fuerza con que aparece en sus versos la afirmación de una mirada femenina sobre el mundo. Junto a la chilena Gabriela Mistral y la uruguaya Juana de lbarbourou, contemporánea suya, conformó la primera avanzadilla en la lucha de las mujeres por ocupar lugares de reconocimiento en los espacios de la literatura de América.

2. Magister en Infancia y Cultura, y Especialista en Infancia, Cultura, y Desarrollo, Universidad Distrital Francisco José de Caldas; Docente, licenciada en Humanidades y Lengua Castellana, Universidad Distrital Francisco José de Caldas. Escritora, articulista, y poeta. En la actualidad, investigadora académica.

Correo: yessikarengifocastillo@hotmail.com

ORCID: https://orcid.org/0000-0001-9940-5531

Google Académico: https://scholar.google.com/citations?user=YiKBOKAAAAAJ\&hl=es

3. Contador Público de la Universidad Nacional de Buenos Aires, ex docente universitario, gerente en empresas de plaza, y asesor de empresas. Escritor, ensayista, y poeta. Ha sido nombrado miembro honorario de la Academia de Literatura de la Ciudad de México. En la actualidad, asesor y jurado Internacional de literatura del Centro Vasco Francés de Buenos Aires.

Correo: hectorjosesanjuas@hotmail.com

ORCID: https://orcid.org/0000-0002-9362-0289

Google Académico: https://scholar.google.com/citations?user=YiKBOKAAAAAJ\&hl=es
} 
En palabras de Susana Martínez Simancas (2004), dice que:

Este sistema dicotómico se ha repetido a lo largo de los siglos (con modificaciones que han ido cuestionándolo) de tal forma que termina por naturalizarse la posición subordinada de las mujeres achacándose esta situación a las diferencias biológicas: la capacidad de engendrar ha marcado negativamente la participación e intervención social de las mujeres.(p.8)

Lo anterior indica que en ese sistema de patriarcado, la mujer es concebida como sujeto inferior en los campos socioculturales (Azevedo, 2014). Por consiguiente, el patriarcado determina que el padre es el que posee el poder y la capacidad de decisiones sobre los integrantes del grupo social. Grupo que es conformado por mujeres y hombres jóvenes, estos últimos algún día asumirán el rol del patriarca mientras que las mujeres, asumirán el papel de subordinadas de por vida (Pérez, 2013).

Al respecto conviene decir que el feminismo ilustrado cuestiona que las características biológicas entre hombre y mujeres, sea suficiente para determinar la subordinación del otro (Ferreyra, 2014). En ese sentido en la obra: "La herencia de la llustración y Simone de Beauvoir", se establece las diferenciaciones en la historia del pensamiento, y las consecuencias morales que este tuvo. Además, la modernidad introdujo el pensamiento naturalista de la igualdad del hombre en palabras como: "todos los hombres nacen libres e iguales," que sirvió para la exclusión de las mujeres en los sectores sociales. Es así como el concepto "hombre" que se aplicaba universalmente, fue establecido por el discurso ilustrado y su dominio, para el nombramiento de los varones. Dejando de lado los principios de igualdad, libertad, y fraternidad, que consolidan los nuevos estatutos del hombre como sujeto social en el Estado Moderno (Tahull, 2016).

Sin embargo, el Estado Moderno no hace parte de la mujer, quien exige su accionar es la naturaleza. Frente a esos planteamientos Mary Wollstonecraft y Olimpia de Gouges exigieron la misma igualdad derechos para las mujeres, que tienen los hombres como el acceso a la ciudadanía, que es elemento esencial del feminismo. La ciudadanía se determina como el mecanismo que garantiza la libertad, una reivindicación necesaria. En la que las mujeres deberán ser posesionadas como ciudadanas, sin esto no son nada. Cabe resaltar que las sufragistas seguirían esa misma línea, obteniendo desde finales del siglo XIX y durante las primeras décadas del 
XX, el derecho al voto y la educación (de Almeida, Santos \& Porto, 2016). Lo que permitió crear movimientos intelectuales como: "La querella de las mujeres," que se caracteriza por generar una reflexión por ambos sexos, acerca de la discriminación de las mujeres. Rastreando voces feministas críticas, que han permitido visibilizar transformaciones sociales desde la mujer (Konieczny, 2015).

En ese sentido surgen grandes voces poéticas, políticas, literarias, y artísticas, que manifiestan sus planteamientos frente a esa desigualdad de género. Una de ellas, es la gran Alfonsina Storni la poeta, la cantante, la escritora, la periodista, la anarquista, y la madre soltera, quien se describe en una conferencia en 1938 así:

El hecho es que, como en otros despierta tarde, y no por tal circunstancia menos acosadora, la afición por la palabra escrita se reveló en mí madrugante. [...] A los ocho, nueve y diez [años] miento desaforadamente: crímenes, incendios, robos, que no aparecen jamás en las noticias policiales. Soy una bomba cargada de noticias espeluznantes. [...] A los doce escribo mi primer verso. Es de noche, mis familiares ausentes. Hablo en él de cementerios, de mi muerte. Lo doblo cuidadosamente y lo dejo debajo del velador para que mi madre lo lea antes de acostarse. El resultado es esencialmente doloroso: a la mañana siguiente tras una contestación levantisca unos coscorrones frenéticos pretenden enseñarme que la vida es dulce. Desde entonces los bolsillos de mi delantal, los corpiños de mis enaguas, están llenos de papeluchos borroneados que se me van muriendo como migas de pan. Desde esa edad hasta los quince, trabajo para vivir y ayudar a vivir. De los quince a los dieciocho, estudio de maestra y me recibo Dios sabe cómo. La cultura literaria que en la Normal absorbo para en Andrade, Echeverría, Campoamor... (p. 33)

En esa dimensión, Alfonsina se preocupó por manifestar sus propias vivencias, e inquietudes. Ofreciendo un universo de posibilidades a sus lectores a la hora de asumir su postura frente al mundo. Manifestando temas como: la naturaleza, la ciudad, la soledad, la incomunicación, el mundo, lo concreto, y lo cotidiano, que representan ese papel que ha ocupado la mujer a lo largo de la historia. Sin embargo, también a menudo, manifestaba su inconformismo con la postura de su padre 
frente a la concepción del llamado "Sexo Fuerte" que se caracterizó por: "no hay llorado/ los hombres de mi raza/ eran de acero" y el dolor que manifiesta su cuerpo se evidencia en: "Así diciendo te brotó una lágrima" un sufrimiento profundo que ella, manifiesta desde la supuesta debilidad femenina y el maravilloso ejercicio racional en : "débil mujer, pobre mujer que entiende", es la herencia de su árbol genealógico tal es el caso de:

Tú me dijiste: no lloró mi padre;

Tú me dijiste: no lloró mi abuelo;

No han llorado los hombres de mi raza.

Eran de acero.

Así diciendo te brotó una lágrima

$Y$ me cayó en la boca... más veneno:

Yo no he bebido nunca en otro vaso

Así pequeño.

Débil mujer, pobre mujer que entiende,

Dolor de siglos conocí al beberlo:

Oh, el alma mía soportar no puede

Todo su peso. (p. 180)

En el anterior poema, se realiza un himno a la concepción que tuvo la familia de Storni sobre el concepto de mujer. Se quisiera añadir que la poesía de Alfonsina refleja las concepciones que ha construido de su madre, quien es una mujer que posee una formación intelectual, que ha debido asumir la crisis económica de su familia, desde un contexto más tradicional que el de su hija. Lo anterior se puede evidenciar en:

Dicen que silenciosas las mujeres han sido

De mi casa materna... Ah, bien pudiera ser...

$A$ veces en mi madre apuntaron antojos

De liberarse, pero, se le subió a los ojos

Una honda amargura, y en la sombra lloró.

$Y$ todo eso mordiente, vencido, mutilado.

Todo eso que se hallaba en su alma encerrado,

Pienso que sin quererlo lo he libertado yo. (p.209)

La tarea ha de centrarse en considerar a la mujer como sujeto político que permea todos los campos sociales, desde posturas críticas, y propositivas, del mundo. En ese sentido el feminismo como un llamado a la reivindicación de la mujer como sujeto derechos, y estrategias como 
la literatura, que acudió Alfonsina para despertar la conciencia de las mujeres frente a sus pensamientos o derechos. Haciéndole resistencia al mandato, lo esperable, y el estereotipo, para alcanzar esa anhelada libertad. Liberándose de la protección de los hombres, reconociendo sus derechos al divorcio, al voto, y la igualdad en todas sus dimensiones.

\section{Referencias bibliográficas}

Azevedo, S. R. J. (2014). La composición histórica de la educación religiosa como componente curricular. Revista Interamericana de Investigación, Educación y Pedagogía, RIIEP, 7(1). DOI: https://doi.org/10.15332/s1657-107X.2014.0001.03

de Almeida, R. R., Santos, M. F., \& Porto, J. C. (2016). Lectura de textos ficcionales y el enfoque escolar de literatura: contribuciones para una Pedagogía de la Elección. Revista Interamericana de Educación, Pedagogía y Estudios Culturales, 9(1), 35-51. DOI: https://doi.org/10.22490/25391887.1925

Ferreyra, H. A. (2014). Mesas Socioeducativas para la Inclusión y la Igualdad. Un programa "De todos con todos". Una experiencia en construcción. Revista Interamericana de Investigación, Educación y Pedagogía, RIIEP, 7(2). DOI: https://doi. org/10.15332/s1657-107X.2014.0002.01

Konieczny, P. (2015). Lorenzo García Aretio: bases, mediaciones y futuro de la educación a distancia en la sociedad digital. Revista Interamericana de Investigación, Educación y Pedagogía, RIIEP, 8(1). DOI: https://doi.org/10.15332/s1657107X.2015.0001.08

Martínez, S. S (2004). La imagen del feminismo y las feministas en la sociedad actual. México, DF

Dora, J.N. (2014). Alfonsina Storni y la sexualidad femenina a inicios del siglo XX. Revista Cultural Mito, 44. Recuperado de http://revistamito.com/alfonsina-storni-y-lasexualidad-femenina-inicios-del-siglo-xx/

Pérez, T. H. P. (2013). Aproximaciones al estado de la cuestión de la investigación en educación y derechos humanos. Revista Interamericana de Investigación, Educación y Pedagogía, RIIEP, 6(1). DOI: https://doi.org/10.15332/s1657-107X.2013.0001.05

Storni, A. (2014). Un libro quemado. Editorial Excursiones. Buenos Aires, Argentina.

Storni, A. (2002). Obras. Prosa, Narraciones, Periodismo. Ensayo, Teatro. Delfina Muschietti, editorial. Buenos Aires, Argentina. P.P 33, 180, y 209. 
Tahull, J. (2016). Modernidad, educación y género. El proyecto inacabado. Revista Interamericana de Investigación, Educación y Pedagogía, RIIEP, 9(2), 159-178. DOI: https://doi.org/10.22490/25391887.1947

Viejo, C. M., Cabezas, I. L., \& Martínez, M. D. J. I. (2013). Las redes de académicas en la docencia universitaria. Revista Interamericana de Investigación, Educación y Pedagogía, RIIEP, 6(2). DOI: https://doi.org/10.15332/s1657-107X.2013.0002.03 